\title{
Framework for developing risk to life evaluation criteria associated with landslides in Canada
}

\author{
Renato Macciotta ${ }^{1 *}$ (D) and Lianne Lefsrud ${ }^{2}$
}

\begin{abstract}
The application of quantitative risk assessments is increasing for decision-making in many industries and contexts, with the evaluation of risks against some adopted criteria. In this article, we review risk criteria developed and used for landslide management, in particular criteria associated with risk to life. We show that while this natural hazard is encountered worldwide, the social and regulatory contexts under which evaluation criteria are developed can vary significantly. Thus, the applicability of developed criteria to any specific situation should be assessed before adopting them elsewhere. We describe selected considerations for developing risk evaluation criteria, propose a framework for defining these criteria in Canada, and assess the applicability of previously proposed criteria. Examples of risk criteria development and adoption for new and existing residential developments and for railway employees are presented to illustrate some of these concepts.
\end{abstract}

Keywords: Risk evaluation criteria, Risk assessment, Decision making, Risk governance, Review

\section{Introduction}

Landslide occurrences are ubiquitous across Canada. They occur in the thousands each year, and landslide types include rock falls, slides and debris flows in the Cordillera, glaciomarine earthflows in the St. Lawrence Lowlands, translational rock slides in the prairies and earthflows associated with permafrost in the northernmost regions (Couture et al. 2013). Fortunately, most landslides do not impact populated areas or infrastructure however a subset affect communication lines, populated areas and other infrastructure. Clague and Bobrowsky (2010) reported an estimated \$200 million in annual costs from landslide effects, and Evans (1999) estimated that over 600 people lost their lives in landslides in the last two centuries for an average of 4 lives lost per year (Couture et al. 2013). The occurrences with the largest number of fatalities (over 10) include: the Frank Slide in Alberta (70 fatalities in 1903), Spences Bridge in British Columbia (15 fatalities in 1905), Notre-Dame-de-la-Salette in Quebec

\footnotetext{
* Correspondence: macciott@ualberta.ca

'David and Joan Lynch School of Engineering Safety and Risk Management, Department of Civil and Environmental Engineering, University of Alberta, 12-324 Donadeo Innovation Centre for Engineering, Edmonton, AB T6G 1H9, Canada

Full list of author information is available at the end of the article
}

(33 fatalities in 1908), Burnaby and New Westminster in British Columbia (22 fatalities in 1909), Cooper mine in British Columbia (56 fatalities in 1915), Britannia Beach in British Columbia (37 fatalities in 1921), Saint-Jean-Vianney in Quebec (31 fatalities in 1971) (Agrawal 2018).

Increasingly, quantitative risk assessments are being used broadly; from examining new industrial facilities to managing existing geohazards (Khan et al. 2015; Morgenstern 1997). Regulatory agencies are requiring the use of quantitative methods in their published regulations and guidelines and clients are aiming to improve the economic efficiency of their risk management decision-making. In landslide management, examples can be found in the implementation of quantitative risk criteria in Hong Kong (ERM-Hong Kong Ltd 1998), and the initiative by the Australian Geomechanics Society to develop risk management guidelines that emphasize quantitative methodologies, in response to local authorities' increasing demands for risk assessments of new urban development (Australian Geomechanics Society (AGS) 2007). In Canada, The province of British Columbia's Guidelines for Legislated Landslide Assessments for Proposed Residential Developments in BC (Association of Professional Engineers and Geoscientists of British 
Columbia (APEGBC) 2010) also considers the application of quantitative assessments for land use planning, and quantitative landslide risk evaluations have been successfully used for decision-making regarding new and existing developments in the provinces of British Columbia and Alberta (Clague et al. 2015; Hungr et al. 2016). Recently, the North American railway industry is developing comprehensive risk management strategies, which are consistently leaning towards more detailed quantitative analyses of track sections, considered critical given their high landslide hazard levels (Macciotta et al. 2016). Canadian guidelines related to landslides also include discussions about measures of landslide risk, risk evaluation and adoption of criteria (Porter and Morgenstern 2013).

Criteria in these studies focus on the risk to the lives of the population exposed. When risk levels are measured in terms of the probability of lives lost, the development of evaluation criteria becomes an increasingly difficult task. Establishing acceptable limits to lives lost is not only a scientific fact-based matter, but also involves the consideration of value-based legal, political, social and economic issues (Aven 2016; Fell 1994; Ho et al. 2000), all influencing landslide risk perception as shown in Prasad et al. (2016) and Heitz and Shimabuku (2017). The final evaluation of risk often lies with the project owner and regulator. Yet, by being informed about the precedents, details, and limitations of the analyses, risk analysts can become valuable advisors in the development and use of such risk evaluation criteria (Leroi et al. 2005).

Given the difficulties outlined above, policy- and decision-makers may be tempted to adopt others' risk evaluation criteria, such as the United Kingdom's (UK) ALARP (As Low As Reasonably Practicable). However, the contexts under which these criteria were developed can be quite different and their applicability to any specific situation should be assessed before adopting them. In this regard, our article describes the primary considerations for developing risk evaluation criteria based on an extensive literature review, proposes a framework for defining landslide risk criteria, and assesses the applicability of previously proposed criteria to a specific context. Two simplified examples discussing some aspects of development of proposed risk evaluation thresholds are also discussed. The paper focuses on the risk to life in the Canadian Context in terms of individual risk -the increase of risk to a particular individual or the average individual associated with the existence of a hazard (Fell et al. 2005)- and societal risk -risk of large number of losses such that the consequence would provoke a socio/political response (Fell et al. 2005).

\section{Existing risk evaluation criteria}

There are several risk evaluation criteria that are becoming commonly used for evaluating landslide risks. The most widely used are the criteria developed by: the Health and Safety Executive (Health and Safety Executive, UK (HSE) 2001) in the United Kingdom for land use planning around industries, the Hong Kong Special Administrative Region Government for land development in landslide prone areas (ERM-Hong Kong Ltd 1998), the Australian National Committee on Large Dams (Australian National Committee on Large Dams (ANCOLD) 2003) and Australian Geomechanics Society for landslides (Australian Geomechanics Society (AGS) 2007), and the U.S. Bureau of Reclamation (2003) for people exposed to potential dam failures. These criteria have been discussed in detail by others (Finlay and Fell 1997; ERM-Hong Kong Ltd 1998; Leroi et al. 2005; Ale 2005; Porter et al. 2009; Scarlett et al. 2011). The acceptable frequency of incidents resulting in lives lost, across such criteria, varies by several orders of magnitude (Frank and Jones 2010). These variances arise from differences in their originating context: the types of companies or organizations proposing the projects (i.e., government agencies versus corporations), the nature of the hazards and associated environmental impacts, the social/political context which affects the nature of risk perceptions, and the philosophical nature of risk evaluation principles embedded in the regulatory structures (Skjong 2002; Vrijling et al. 1998).

The HSE criteria started with a focus on the risks posed by nuclear power plants, whereby low probability accidents have high consequences, with immediate lives lost, and also chronic effects and significantly shorter life expectancy. In this context, consequences are regional, long lasting, and newly imposed (Health and Safety Executive, UK (HSE) 1992). In contrast, slope failures in developments within landslide prone areas, such as for Hong Kong landslides (ERM-Hong Kong Ltd 1998), the consequences are localized, immediate, and not long term. Hong Kong is also densely populated and characterized by its hilly terrain. As such, the development of areas unaffected by landslides is not always an option. In such a context, even when there is a long history of landsliding (ERM-Hong Kong Ltd 1998), too conservative approaches towards development regulations would lead to significant economic losses related to limitations in land use. As a result, there is a sense of higher tolerance towards these risks (Fell 1994; Finlay and Fell 1997). In sum, the Hong Kong criteria would be less applicable in regions where population density is low and more area is available for new development. However, the Hong Kong criteria has been used successfully as basis for landslide prone areas in Canada (District of North Vancouver and the Cheekye debris fan in British Columbia, and the Cougar Creek debris fan in Canmore, Alberta - Clague et al. 2015; Hungr et al. 2016).

The variability in these contexts suggests that the development of risk evaluation criteria is best suited when 
defined at regional, industry, client and even case specific scales. Existing criteria can be helpful as starting point for the development of risk evaluation thresholds, given the context of the system matter of analyses is similar. In any case, however, the applicability of previously proposed criteria should be assessed before it is adopted.

\section{Framework to develop risk evaluation criteria}

The development and adoption of risk acceptability thresholds will be influenced by the organizational, environmental, and social/political context of the project (Rowe 1977; Fell 1994; Fell et al. 2005; Leroi et al. 2005). As shown in Fig. 1, any framework for the development of risk evaluation criteria needs to consider three main aspects in an integrative manner (Aven 2016; Renn 2008). The first aspect, the characteristics of the system being analysed - including the project owner, project, and its environment - is technical in nature. It considers the hazard characteristics, such as extent and type of consequences, frequencies of occurrence, and the associated uncertainties. The second aspect is the social, political, economic and cultural context. This aspect is fundamentally of social nature, which affects how risks are perceived depending upon if they are natural or manmade, existing or newly imposed, voluntary or involuntary and, as a result, how risk responses become amplified or attenuated. The third aspect, the principles for developing risk evaluation criteria, has a philosophical nature as dependent upon the technical and social contexts and the principles of regulation. We draw from these fundamental principles to develop risk criteria (Pandey and Nathwani 2004; Skjong et al. 2005; Vanem 2012; Morrison 2014).

\section{Principles for developing evaluation criteria}

Selecting the principles that would lead to a clear framework for risk criteria development should address three important considerations: 1 ) the need to regulate risks

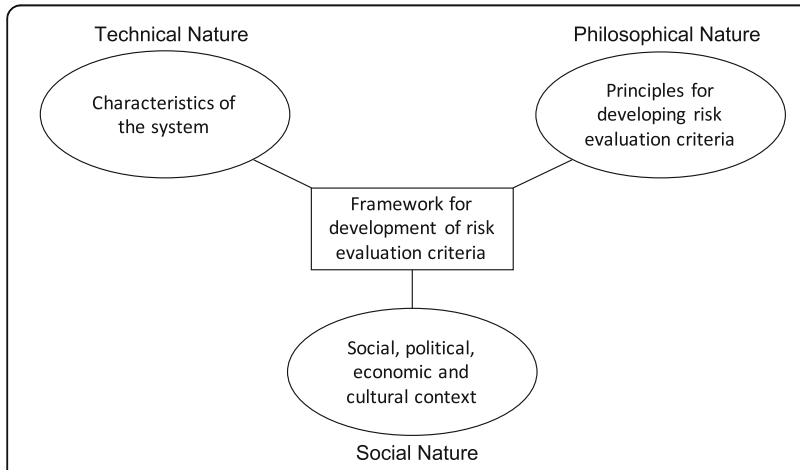

Fig. 1 Aspects (ellipses) to be considered within a framework for developing proposed risk to life evaluation criteria posed by nature and development; 2) risk thresholds to aid in evaluating the real urgency for mitigation strategies, risks deemed as not tolerable would require mitigation to assure a minimum quality of life; and 3) the uncertainties inherent to a system that must be considered during assessment and management, including precautionary approaches when required. Several principles are embedded within this (Aven 2016; Vanem 2012).

- Absolute risk criterion: The level of risk itself is studied and the risk criterion is formulated as a maximum level of risk that should not be exceeded, without regard to the cost and benefit associated with it.

- Precautionary principle: If risks are irreversible, scientific uncertainty is not a justification for postponing cost-effective mitigation measures. If the uncertainty and consequences are too great, then it may be best not to assume the risks at all.

- The principle of equivalency: Risk should be compared with known levels of risks from similar activities or systems that are widely regarded as acceptable or tolerable, to require that an equal level of risk be obtained. Similarly, comparisons can be against historic data, natural disasters, and life expectancy.

- The holistic principle: Decisions regarding safety on behalf of the public should be based on a holistic consideration of all risks and apply across the complete range of hazards. Only when the total risk the public is exposed to is properly assessed, can the proposed risk reduction measures be evaluated and risk criteria established. Given the difficulties and effort this would require, the principle is applied at the scale of the system being analyzed and requires simplification (such as apportioning and scaling).

- The ALARP principle: Risks should be managed to be As Low As Reasonably Practicable (ALARP).

Both risk levels and the cost associated with mitigating the risk are considered, and all risk reduction measures should be implemented as long as the cost of implementing them is reasonably practicable according to cost effectiveness considerations. This requires the weighing of risks versus benefits/expectations, with a maximization of benefit and minimization of harm.

- The accountability principle: Transparent and clearly defined criteria, which should be quantitative rather than qualitative and based on objective assessments (as far as possible) rather than subjective interpretation of risk. The formulation of the criteria should be explicit, rendering little room for different interpretations of the evaluation criteria themselves.

The framework should be consistent with these principles and with common practice in other industries. As 
such, it considers proposing threshold values for acceptable and tolerable risks. Risks above the tolerable threshold are considered not tolerable and risk mitigation is mandatory. An ALARP region is placed below the tolerable threshold. If the owner / regulator decides on adopting an acceptability threshold (risks below this threshold need no further reduction), the ALARP region lower boundary is determined by it. Elsewise, the ALARP concept is applied to all risks lying below the tolerable threshold.

The framework also considers risks to be assessed in terms of the individual risk (for the individual estimated to be at highest risk) and societal risk (through F-N plots). F-N plots consist of log-log plots with the number of fatalities on the horizontal axis $(\mathrm{N})$ and the probability of $\mathrm{N}$ or more fatalities on the vertical axis (F). The proposed thresholds for risk acceptability and tolerance are drawn as lines with negative slopes to show risk aversion towards accidents involving large number of fatalities. F-N plots are common practice in industries such as nuclear-power generation, land use planning around industries, dam operations, maritime industries, and land development in landslide prone areas (Health and Safety Executive, UK (HSE) 1992; Morgenstern 1995; Ho et al. 2000; Health and Safety Executive, UK (HSE) 2001; Leroi et al. 2005; Skjong et al. 2005; Porter et al. 2009, Scarlett et al. 2011). A point in the F-N plot (anchor point) and a slope of a line are required to building a risk threshold line. The anchor point is a threshold cumulative probability for a certain number of fatalities, typically $N=1$. The slope of the line is typically defined between -1 and -2 , being -1 mostly adopted. A slope of -1 in the F-N curve corresponds to reducing the tolerable threshold (cumulative frequency, $\mathrm{F}$ value in the vertical axis) by one order of magnitude for each increase in the number of fatalities $(\mathrm{N}$ value in the horizontal axis) by one order of magnitude. Others (Skjong 2002; Ale 2005; Skjong et al. 2005; Center for Chemical Process Safety (CCPS) 2009; Vanem 2012) discuss the implications of the slope chosen.

\section{Proposed framework for developing risk evaluation criteria}

The proposed framework is presented in Fig. 2. It has been divided in three major stages according to the parties that lead the analyses. The first stage is carried out through a coordinated effort between the risk analyst and the owner / regulator and must to be consistent with the risk analysis scope of work. The three steps proposed should be thought of while defining the output of the analysis (or how is risk to be measured), as the criterion and estimated risks need to be compatible.

Those affected include: 1) Employees, who are those exposed to the hazard in exchange of economic or professional gain, 2) Users, who are those exposed to the hazard in exchange of a gain or to cover a need, and 3) Public, who are people exposed to the hazard not being aware of any direct benefit in exchange. This grouping is fundamentally about defining voluntary versus involuntary risk levels and risks versus benefit trade-offs, which is then used for characterizing the type of risk. As previously discussed, the framework proposes to assess the risks in terms of individual and societal risks. However, there can be systems where societal criteria are not necessary, such as systems where the maximum number of people exposed is small (railway freight crew members usually travel in groups of 2).

The second stage is carried out by risk analysts given their acquired knowledge of the entire system. The steps in this stage need to be followed for each population type and for individual and societal risks, as applicable. The steps, assumptions, and principles behind the development of the proposed criterion need to be clearly stated, as they will be reviewed in the later stage by the owner / regulator and, ideally, the population exposed. When possible, more than one option for the proposed thresholds should be presented. In that case, the differences in the fundamental thinking behind each proposed threshold should also be stated. The second stage starts with a characterization of the risks according to 1) is it a new or existing slope, facility or system. This includes differentiating between man-made structures (road cuts and reservoirs) and natural slopes, and 2) is the risk voluntary or involuntary, which follows the population classification in the first stage. The remainder steps (5 through 8 in Fig. 2) develop the proposed risk thresholds, the ALARP principle evaluation criterion, and how to apportion and scale the proposed criterion within the system, when applicable.

The last stage is the responsibility of the owner and/or regulator. It consists of making final decisions and adjustments to the developed criteria considering the social, economic, political and cultural context. The risk analyst acts only as an advisor and it is strongly recommended for the public to be involved in the decision-making. This implies simple and clear explanations of the risk analysis process, its limitations, and the development of the criterion as well as the principles behind it. It will require a good risk communication strategy and proper risk/benefit distribution among those exposed.

The risk criterion should be reviewed and periodically updated in light of changes in both the hazard (stabilization, changes in technology, new measurements) and the elements at risk (changes in public expectations, exposure).

\section{Methods for developing proposed risk thresholds}

There are several methods for developing proposed risk thresholds, which are subject to continuous debate in 


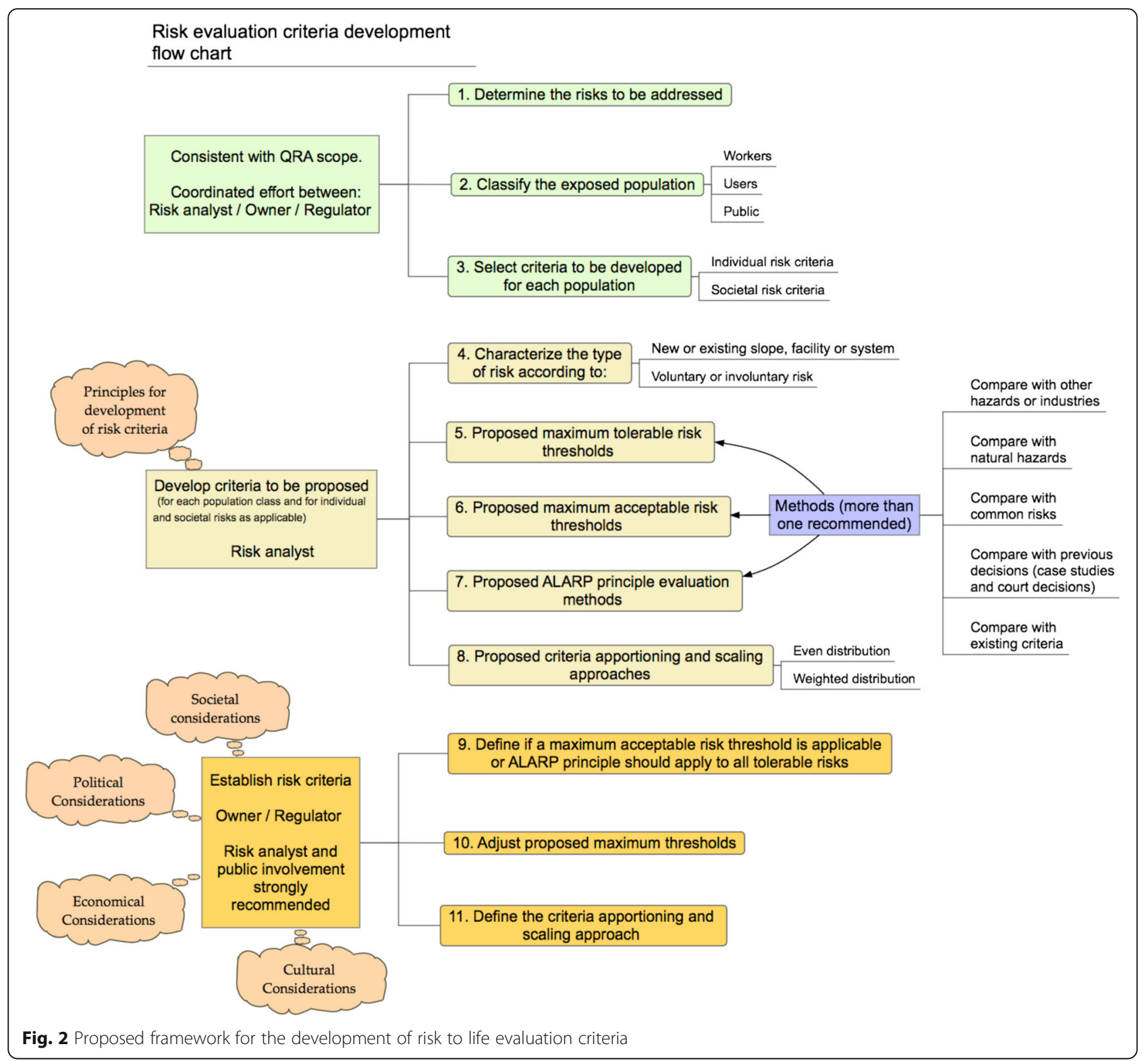

the literature. Methods available are (after Morgenstern 1995; Skjong 2002; Center for Chemical Process Safety (CCPS) 2009):

1. Comparison with statistics within the industry or for similar industries and activities

This method implies that, if the industry or activity chosen for comparison is currently taking place, the risks associated with it are considered in balance with the benefits gained. The activity chosen needs to reflect the same risk characteristics as the system being assessed (voluntary or involuntary). For example; the railway passenger industry should be as safe as the air passenger transportation industry.

\section{Comparison with natural hazards}

This method consists of comparing the system to statistics on lives lost due to natural events. It implies that the risks we impose on ourselves should be a small portion of what can be blamed on nature. For example; the annual risk to the public imposed by the slope cut should be equal or less than the risk associated with thunderstorms.

\section{Comparison with common risks}

This implies the imposed risks by the system analyzed should not be greater than risks from common activities such as swimming and driving. Example: The risks 
associated with landsliding along a section of the highway should be less than those associated with crossing the street or driving the highway.

\section{Comparison with previous decisions}

In this method, owners, regulators or court decisions on cases where the risks involved can be estimated are taken as indicative of society's tolerance of a particular activity or industry.

\section{Comparison with existing criteria}

In this method, previously proposed criteria for systems reflecting risk characteristics similar to the ones being assessed are used for comparison or validation. Example: Tolerable risks from landsliding for land development areas should be similar to those proposed in Hong Kong.

When developing proposed landslide risk thresholds it is important to keep in mind the considerations presented by IUGS (1997). These considerations are consistent with the principles presented here and can be summarized as follows:

- Incremental risk associated with the system analyzed should not be significant when compared to the risks associated with everyday life, and whenever possible the ALARP principle be applied,

- Events with the potential to cause a large number of fatalities should have low occurrence probabilities. This accounts for society's lower risk tolerance of large numbers of fatalities,

- Some populations tolerate higher risks than others in relation to the required efforts to mitigate those risks, as they benefit from their existence or the activity realized (workers in the mining industry as opposed to the public), and;

- Tolerable risks are higher for natural hazards than for those engineered or controlled (i.e., natural slopes versus slope cuts, earth fill dams, or even for natural slopes that are known to be monitored).

\section{Methods for evaluation of the ALARP principle}

One method to evaluate if the ALARP principle is being met is through conventional cost-benefit analyses. Here, the costs of implementing risk reduction measures are compared against the reduced risks in monetary units, thus assigning an economic value to life. Some estimates of the economic value of life appear in the literature, mainly considering people as a resource in an economic activity, however this approach conflicts with ethical traditions (Skjong 2002).
A preferred method is the use of a cost-effectiveness analysis (Skjong 2002; Skjong et al. 2005). This method calculates a ratio of the cost of implementing risk reduction measures to the reduction in risk, thus avoiding putting an economic value to life. According to Leroi et al. (2005) two commonly used variants of the method are the adjusted cost-to-save-a-statistical-life (ACSSL) and the unadjusted cost-to-save-a-statistical-life (UCSSL). These are analogous to the gross-cost-of-averting-a-fatality (GCAF) and the net-cost-of-averting-a-fatality (NCAF) respectively, as presented in Skjong (2002) and Skjong et al. (2005). These can be defined as (Leroi et al. 2005, p. 167):

$$
\begin{aligned}
\mathrm{ACSSL} & =\frac{C_{A}-(E[\mathrm{bef}]-E[\mathrm{aft}]}{L[\mathrm{bef}]-L[\mathrm{aft}]} \\
\mathrm{UCSSL} & =\frac{C_{A}}{L[\mathrm{bef}]-L[\mathrm{aft}]}
\end{aligned}
$$

Where:

$C_{A}$ is the annualized cost of implementing the risk reduction measure in dollars per year, $E[$ bef $]$ and $E[$ aft $]$ are the economic risks (failure probability times monetary loss) in dollars per year before and after implementing the risk reduction measures, $O[\mathrm{bef}]$ and $O[\mathrm{aft}]$ are the annual operational costs before and after implementing the risk reduction measures, and; $L$ [bef] and $L[\mathrm{aft}]$ are the estimated risk to life in lives per year before and after implementing the risk reduction measures.

When implementing this method for evaluation of individual risk, the value of $\mathrm{L}$ is the value of risk (annual probability of the individual being killed). When evaluating societal risk, the value of $\mathrm{L}$ can be estimated as the total risk, $\Sigma f_{i}$. $N_{i}$ where $f_{i}$ and $N_{i}$ are the annual probability (or frequency) and the correspondent number of lives lost, respectively.

This method is also useful for comparison of different risk mitigation options. More expensive options give larger CSSL (cost-to-save-a-statistical-life, either adjusted or unadjusted) values, while more effective options will give lower CSSL values (larger reductions in risk). However, assessing if the ALARP principle has been satisfied requires a criterion regarding the CSSL values considered cost-effective. Deciding what is considered to be cost effective CSSL values is not a simple matter. Risk reduction will have a direct economic impact on the owner, which could ultimately lead to an activity not being profitable. As a consequence, the workers might also be economically impacted (loss of jobs or income reduction). Where the regulator is also responsible for safety, thus having to pay for the risk reduction measures, the public is economically affected (their taxes pay for the reduction of risk).

Given these complexities, it is suggested that for estimated risks falling within the ALARP region, the risk 
analyst estimate the CSSL values for the risk mitigation measures proposed as part of the risk management process and final decisions should be left for the owners and regulators. When presenting the information, not only the CSSL ratios should be included, but also the actual increment in cost associated with the mitigation strategy and the estimated risks after their implementation. These absolute values are as useful as the CSSL for the decision-making process. The participation of the public through surveys or public meetings should be encouraged, as they are part of the exposed population and are likely to be impacted economically by the decisions.

\section{Methods for apportioning and scaling criteria}

Risk criteria are often defined for a certain scale of the system. These criteria need to be adjusted to reflect the scale of the particular system evaluated or have to be apportioned throughout the sub-systems for their individual evaluation (for example risks along a particular segment of road as opposed to the entire transportation corridor). If the criteria are not scaled or properly apportioned, higher risks than desired could end up being tolerated. A detailed discussion is presented in CCPS ( 2009).

An example is used to illustrate the concept. Typical systems analyzed are new developments within landslide prone areas or existing/proposed alignments of highways. Risk criteria can then be defined for the system (either the new development or the highway). The risk value to be evaluated against the selected criterion is the integration of the risks associated with all hazards and sectors within the system (all slopes, all potential failure volumes, every mile along the highway, and considerations of all other ground hazards). In practice, however, it is unlikely that all hazards and sectors be considered due to time constrains, budget limitations, or scenarios deemed negligible. To account for the different sectors (i.e. mileage along the highway), the criterion needs to be apportioned. If the apportioning is based only on the linear or aerial extent of the system, (same risk thresholds for each mile along the highway or for each slope within the proposed development), it is an even apportioning or distribution. It is often the case, however, that a number of sectors will be more hazardous than others. In cases where the analyst is aware of this variability in hazard levels, an even apportioning could lead to criterion that is too strict at some locations and not a reflection of the defined overall criterion and perception of risk. Apportioning the criterion with considerations of the relative hazard levels or the exposure of the population would be a weighted apportioning or distribution. The criteria for defining the weights for apportioning will reflect the perceived variation in hazard levels through the entire system and for all potential hazards in light of the available knowledge and information.
Weighted or even apportioning should reflect the existing understanding of the situation and the adequacy of apportioning criteria based on even distribution of risk or weighted distributions needs to be assessed for each particular case. Apportioning criteria should be reviewed and periodically updated together with the risk estimations and in light of risk analyses of hazards not previously assessed.

\section{The issue of low probability - High consequence events} When assessing societal risks, the issue of high consequence events (large number of fatalities) having extremely low, but existent, occurrence probabilities, arises. These risks are difficult to quantify, and are often the most worrisome as well (Oldenburg and Budnitz 2016). Although some methods have been used to analyse these risks (Oldenburg and Budnitz 2016) and to quantify them (Cadini et al. 2017; Mignan et al. 2014), tolerable thresholds are difficult to define for systems where large populations are exposed (densely populated developments where hundreds to thousands of people can potentially be affected - such as communities downstream of dam facilities). It can be argued that on these circumstances the precautionary principle be applied. This principle states that where there are threats of serious consequences, all cost-effective measures to prevent them should be applied. In our context, this would imply that where the consequences are unknown but may be judged by some to be of catastrophic magnitude (large number of fatalities), it may be better to implement all known risk control measures or even to abandon the project rather than to accept the uncertain but potentially high risk (Skjong 2002). In this context, risk aversion would play an important role in the decision-making process for systems that could be associated with low probability but high consequence events (Cha and Ellingwood 2012). An example of the higher risk aversion towards large number of fatalities is the adoption of a vertical cut-off for tolerable risk thresholds when assessing the risk to developments in landslide prone areas in Hong Kong (Leroi et al. 2005). It is noted, however, that the precautionary principle needs to be considered with care, as avoiding a risk is typically associated with incurring in other risks (i.e. economic stagnation, crisis in the housing market if new developments are stopped, lack of employment, insufficient power, water or transportation services).

\section{Results and discussion on risk evaluation criteria for residential areas in mountainous terrain}

This section presents a discussion on validating the adoption of existing risk evaluation criteria for landslide phenomena through statistical databases and precedent cases, particularly for defining acceptability and tolerability thresholds. 
Figure 3 presents a schematic illustration of existing and proposed residential areas in mountainous terrain. For simplicity, only three dangers are highlighted in this figure: Natural slope instabilities (deep seated slides, shallow slides, snow avalanches, rock falls, rock avalanches), river flooding, and periodic debris flows that shape the observed depositional fan.

Porter et al. (2009) describe a case in the District of North Vancouver (DNV) where risk to life evaluation criterion was adopted as part of a quantitative risk assessment for developments in landslide prone areas. The Hong Kong evaluation criterion (ERM-Hong Kong Ltd 1998) was selected on the basis of having a similar legal system (Common Law Legal System inherited from the United Kingdom) and to be developed for a similar context. The criterion developed in Hong Kong was based on previous studies for diverse industries within and outside the region (Dam management, transportation, nuclear power plants). Details on the definition of the criterion are presented in ERM (1998). The decision of adopting the Hong Kong criterion was supported by consultant's recommendations and informal feedback from the public. Porter et al. (2009) postulated that the Hong Kong tolerance criterion might be appropriate for application in Canada. These criteria were also used as basis for decision making in other Canadian cases, development in Cougar Creek and Cheekye fans (Clague et al. 2015; Hungr et al. 2016).

\section{Individual risk criterion}

Figure 4 presents the Hong Kong tolerable individual risk thresholds. The criterion allows for risks associated with existing situations to be one order of magnitude higher than for new situations. Figure 4 also shows the thresholds adopted by other organizations (HSE, ANCOLD and AGS). It is not surprising the risk thresholds are common between different organizations, which typically adopt the considerations and the methodology followed by the HSE (1992 and 2001). Definition of the Hong Kong criterion (similar to the HSE criteria) mainly relied on assessing how common risks to the exposed population are related to the population's background risk (age standardized death probability by all causes).

The Hong Kong criterion is then compared to risks posed by activities common for the Canadian population in order to assess its applicability to the Canadian context. The tolerable risk threshold for new situations appear to be in the order of those risks imposed by air travel and drowning, and about an order of magnitude lower than for motor vehicle accidents. It is considered the population is willing to tolerate these risks related to transportation (for the case of air travel and motor vehicles) and their interaction with water bodies (for recreation purposes in pools and lakes). Risk tolerance for new situations in Canada can then be proposed to be about the same order of magnitude, which supports the adoption of the Hong Kong criterion. The threshold is further supported by the estimation of Porter et al. (2009) that this risk value (1E-5) corresponds to less than $0.2 \%$ incremental risk, which can be considered low. For existing situations, a proposed threshold value one order of magnitude higher would be about the risk of death due to motor vehicle accidents and lower than the risk of death due to all accidents.

It is believed the most important step in developing the risk criteria is its validation by the public exposed. In the case of the DNV described in Porter et al. (2009), a public task force convened by the DNV supported the adoption of the Hong Kong criterion based on a number of public meetings and public surveys.

Regarding acceptability thresholds, the HSE adopts a value of $1 \mathrm{E}-6$, which for the Canadian context is about the same order of magnitude than events considered extremely rare (such as death by lightning in Fig. 4). It also represents an increase of less than $0.02 \%$ in the standardized risk of death for the population. However,

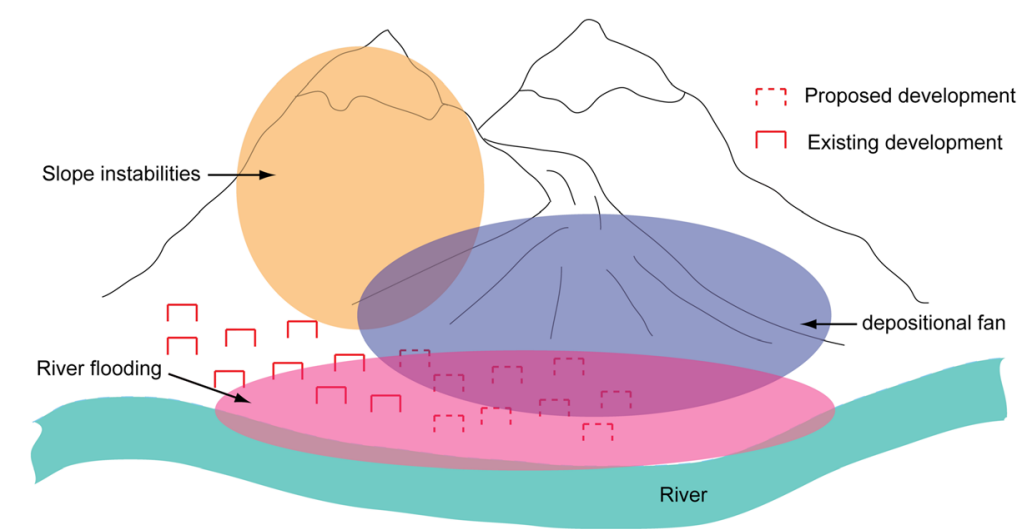

Fig. 3 Schematic illustration of existing and proposed residential areas in mountainous terrain highlighting some potential ground hazards 


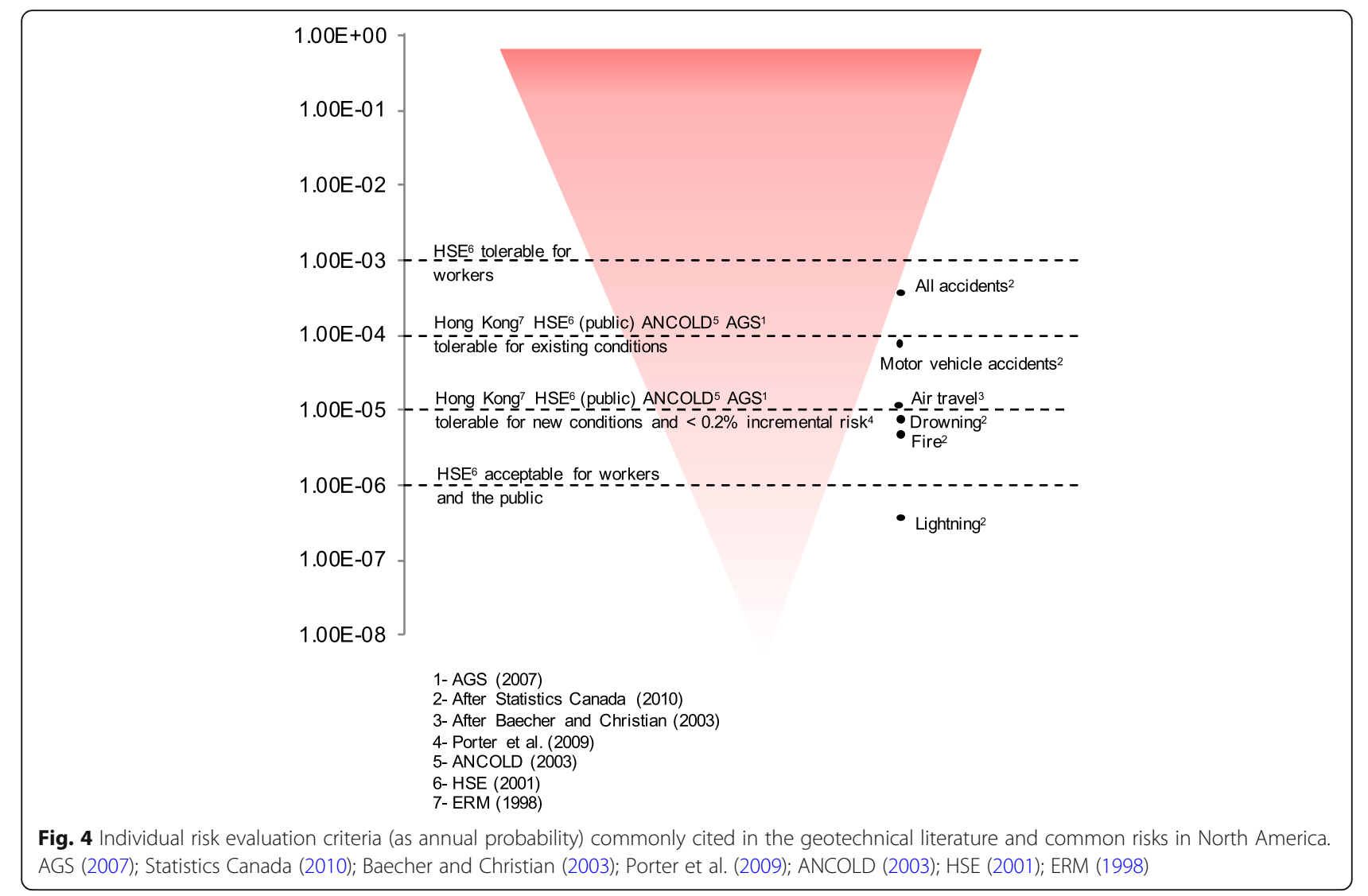

deciding if an acceptable threshold is to be adopted below which the ALARP principle is not mandatory, is responsibility of owners and regulator and should be done in consultation with the exposed population.

\section{Societal risk criterion}

Figure 5 presents the Hong Kong societal risk criterion (a) and criteria adopted by other organizations (U.S. Bureau of Reclamation 2003; Australian National Committee on Large Dams (ANCOLD) 2003; and Health and Safety Executive, UK (HSE) 1992 and 2001) (b). Unlike the individual criteria, the societal criteria vary among these organizations. This corresponds to differences in the type and scale of the hazards being evaluated and the number of people exposed. The Hong Kong criterion was chosen given the similar hazard context for which it was proposed (development is landslide prone areas).

Two court decisions published in the geotechnical literature where chosen to assess the applicability of the Hong Kong criterion. Both decisions implied the risks to the public were considered intolerable. The risk values were estimated after the decisions were made. The first case corresponds to rock fall hazards along a highway (Bunce et al. 1997) where a rock fall impacted a vehicle and killed one person. The second case corresponds to a proposed development in the path of a potential debris flow (Porter and Morgenstern 2012). Both estimated risks are plotted in Fig. 5 and lie above the tolerable threshold line.

The Thredbo landslide in Australia (Mostyn and Sullivan 2002) is also plotted in this figure given the similar social and economic context. This suggests that the Hong Kong tolerable threshold might be applicable in the Canadian context for new developments. It also suggests that increasing the threshold one order of magnitude might not be applicable for existing developments, although more published cases should be analyzed. This is further validated by its recent application in some Canadian cases.

The cut-off values adopted in Hong Kong for the area of intense scrutiny (between 1000 and 5000 fatalities) corresponds to a local policy, and its adoption needs to be based on political and social considerations. Again, here the involvement of regulator, consultant and the public is of critical importance. The same applies to the acceptability threshold.

\section{Apportioning the risk criterion}

The Hong Kong criterion was defined for a given areal extent, or "Consultation Zone" (ERM-Hong Kong Ltd 1998). The Consultation Zone in ERM (1998) was defined as "... the area of natural terrain that must be considered.." in the analysis (ERM-Hong Kong Ltd 1998), and consisted of the summit of the slope, the slope itself and up to a 


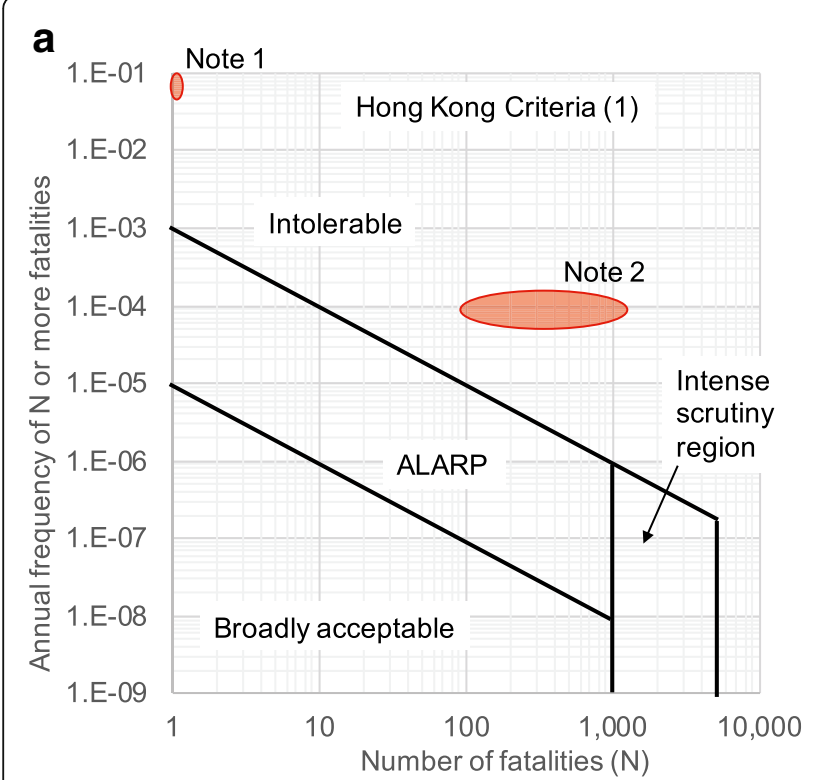

Note 1: Rock fall case along a highway in $\mathrm{BC}(6)$

Note 2: Proposed development case in BC (5) b

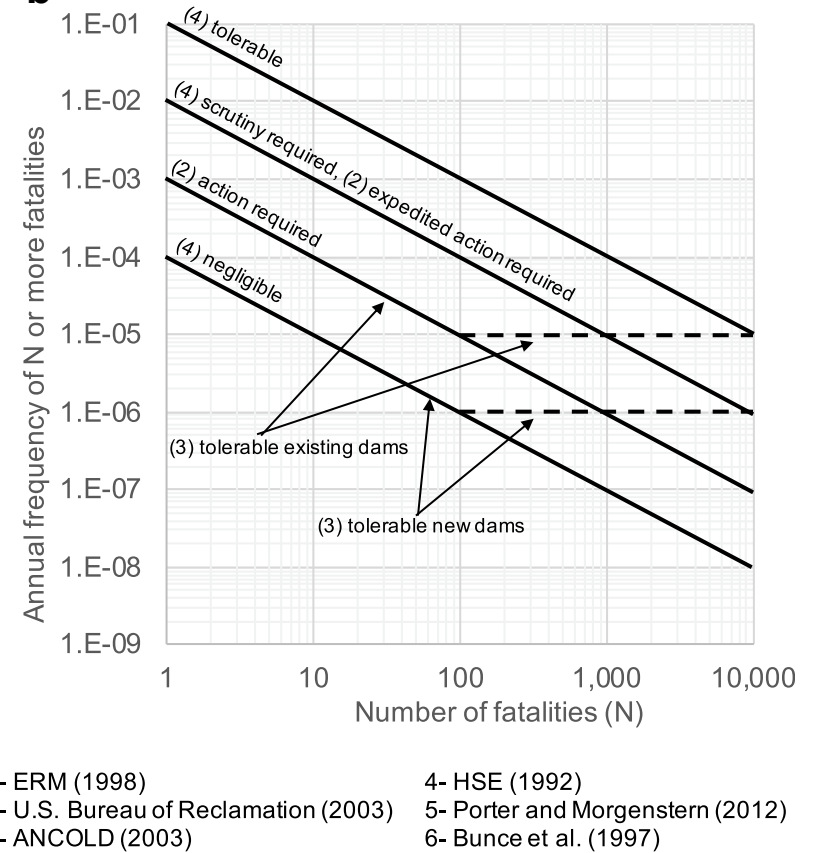

Fig. 5 Societal risk evaluation criteria. a Criterion proposed in Hong Kong for developments in landslide prone areas and cases where risks were found to be intolerable. $\mathbf{b}$ Criteria commonly cited in the literature

distance of $150 \mathrm{~m}$ from the toe of the slope; and for a length of $500 \mathrm{~m}$. Porter et al. (2009) proposed a definition of the consultation zone for the Canadian context as: "The Consultation Zone shall include all proposed and existing development in a zone defined by the approving authority that contains the largest credible area affected by landslides, and where fatalities arising from one or more concurrent landslides would be viewed as a single catastrophic loss". This implies that the criterion is applicable to the area of influence of the hazard, and doesn't need to be scaled for the size of the Consultation Zone.

However, evaluation thresholds are applicable when all risks posed are integrated. If other hazards are considered negligible when compared to landslide hazards, the criterion described can be readily applicable to evaluate landslide related risks in the area. If the risk analysis is comprehensive regarding all hazards, the overall risk can also be readily assessed against the criterion. It is common for risk analyses to focus on one or a few particular hazards. The existence of other potential hazards needs to be considered when adopting threshold values for risk evaluation. Qualitative or relative risk assessments can shown to be useful to apportion the risk thresholds among hazards. If this information is lacking, a conservative approach can be to scale the thresholds to one order of magnitude lower, as long as no other hazard is deemed to pose higher risks than the one being evaluated.

\section{Application of the ALARP principle}

Once a risk analysis is performed and the calculated risks are evaluated against the criteria defined for this context, risks within tolerable thresholds need to be evaluated against the ALARP principle. As previously discussed, this would require evaluating the reduction of risk given potential mitigation strategies to further reduce risk, and the costs of these strategies (capital and operational costs). The feasibility for further risk reduction would become dependent of the available operational budget and the population's perception of risk. Balanced decisions will render minimum residual risks within tolerable thresholds, without overstressing available resources, and optimized through evaluation of different options through ACSSL or UCSSL comparisons.

\section{Results and discussion of individual risk thresholds for railway employees exposed to landslides based on accident statistics and comparison to other criteria}

This section presents a brief example on developing proposed acceptable and tolerable individual risk thresholds based on statistical data and validation against other criteria in similar contexts.

According to WorkSafeBC (2009), transportation and related services is one of the high-risk economic activities in the province of British Columbia. Within the railway industry, train crew members and maintenance-of-way (MOW) 
personnel are the most exposed to operation hazards, which include a variety of ground-hazards such as rock falls, embankment settlements, river erosion, and rock and soil slides.

\section{Acceptable risk threshold}

Proposing a threshold for risk acceptability involves answering the question of how much risk increment we are willing to accept. In this example an acceptability policy of zero risk increase is adopted. As long as the accidental risks during working hours do not exceed the average accidental risks for other causes, it can be considered that the activity does not impose an increase on the individual's risk. Average risk to life statistics can then be used for calculating these thresholds.

It is assumed the employee's age is between 20 and 49 years. Figure 6 shows the annual life loss probability for the average Canadian resident within that same age group.

For this age group, the average risk increment caused by work and non-work accidents is about 1.9E-4. Of course, this accident-related increment in risk is distributed throughout the day. In order to estimate the incremental risk corresponding to the period a crew member spends working, the following assumptions were made:

- Three periods of time where distinguished: working, sleeping and other (i.e. recreational),

- The average employee spends about $30 \%$ of the time working each year,

- The average employee spends $30 \%$ of the time sleeping ( 7 to $8 \mathrm{~h}$ a day in average),

- Accident-related increase in risk while sleeping is perceived by the population to be acceptable, and therefore it is used as a benchmark for proposing risk acceptance thresholds, and;

- All accidents during the working period are considered work-related.

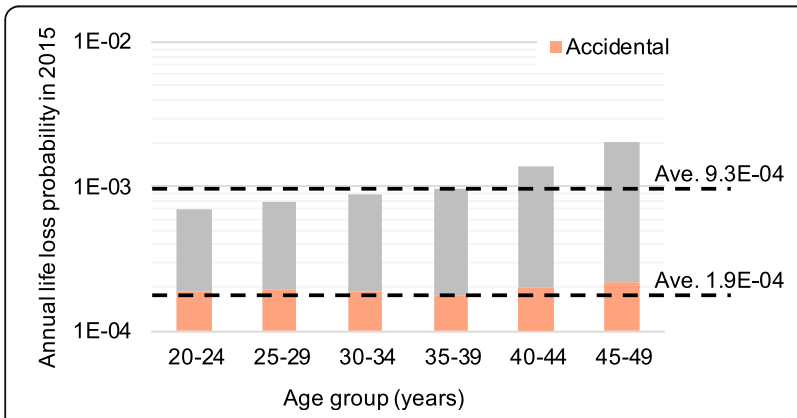

Fig. 6 Annual life loss probability per age group based on the Canadian population mortality rates 2015 (Statistics Canada 2018)
Table 1 shows the distributed accident-related risks for the average employee following these assumptions. Table 1 suggests that accident-related risks during working hours are about $5.7 \mathrm{E}-5$ per year. Conservatively, an annual individual risk threshold of $1 \mathrm{E}-5$ can be proposed. This is consistent with the Hong Kong criteria (ERM-Hong Kong Ltd 1998) for new developments, however is one order of magnitude higher than the HSE ( 2001) broadly acceptable criteria.

\section{Tolerable risk threshold}

Proposing tolerable risk thresholds requires understanding the increase in risk the workers are willing to tolerate in exchange for the benefits of the activity. It will be argued in this example that average fatality statistics for particular activities reflect risk levels the average worker is willing to tolerate, and will be taken as lower than maximum tolerable risk thresholds. This can then be proposed as maximum starting point for regulators and owners to decide if these are deemed adequate or further decrease is necessary.

Work-related accident statistics can aid in quantifying activity-associated risks. These statistics for the province of British Columbia (WorkSafeBC 2009) were used to estimate the workers annual probability of death for four high-risk sub sectors of the economy.

Table 2 presents the analysis. Also shown is the analysis for a low-risk sector as a reference. From these statistics, and considering that the estimates include workers exposed to variable levels of risk; a tolerable individual risk threshold of $1 \mathrm{E}-3$ can be proposed. This is consistent with HSE individual risk tolerable threshold for workers (Health and Safety Executive, UK (HSE) 2001), considered as being developed for a similar socioeconomic context.

\section{Application of the ALARP principle}

Similar to the previous example, estimated risks within tolerable thresholds need to comply with the ALARP principle. In the case of railway operations, options for further risk reduction would require comparison of different options through their ACSSL and UCSSL values, and balanced decisions will render minimum residual risks, with optimal allocation of available resources, at costs that maintain profitable operations.

Table 1 Accident-related risks for railway crew members and MOW personnel distributed throughout the day

\begin{tabular}{|c|c|c|c|c|}
\hline & \multicolumn{3}{|l|}{ Activity } & \multirow[t]{2}{*}{ All } \\
\hline & Working & Sleeping & Other & \\
\hline \% Time & $30 \%$ & $30 \%$ & $40 \%$ & $100 \%$ \\
\hline Accident-related risk & 5.7E-5 & $5.7 \mathrm{E}-5$ & $7.6 \mathrm{E}-5$ & $1.9 \mathrm{E}-4$ \\
\hline
\end{tabular}


Table 2 Employee annual death probability by sub sector estimated from work-related accident statistics by WorkSafeBC (2009)

\begin{tabular}{|c|c|c|c|c|c|}
\hline Sub Sector & Fatalities per year $^{\mathrm{a}}$ & Claims per year ${ }^{\mathrm{b}}$ & Fatalities per Claims ${ }^{c}$ & Injury Rate ${ }^{d}$ & Annual Probability of death \\
\hline Transportation and related services & 26.6 & 4098 & $0.65 \%$ & $5.8 \%$ & $3.77 \mathrm{E}-4$ \\
\hline Construction & 33.6 & 8759 & $0.38 \%$ & $5.9 \%$ & $2.24 \mathrm{E}-4$ \\
\hline Forestry & 13.8 & 720 & $1.9 \%$ & $6 \%$ & $1.14 \mathrm{E}-3$ \\
\hline Oil and gas or mineral resources & 7.4 & 388 & $1.9 \%$ & $2 \%$ & 3.80E-4 \\
\hline Business services & 1.2 & 711 & $0.17 \%$ & $\begin{array}{l}0 \% \\
\text { (less than } 0.5 \% \text { ) }\end{array}$ & $<8.50 \mathrm{E}-6$ \\
\hline
\end{tabular}

Annual probability of death is estimated as $\mathrm{c}$ ) $\mathrm{x}$ d) obtaining average number of fatalities per number of workers per year. Assumed to be an approximate measure of the likelihood of work related death of an average worker in 1 year

${ }^{a}$ Average number of accepted fatal claims per year between 2005 and 2009

${ }^{\mathrm{b}}$ Average number of accepted claims per year (short-term, long-term and fatal claims) for 2008 and 2009

cratio of ${ }^{a}$ respect to ${ }^{b}$

${ }^{d}$ Average number of claims (short-term, long-term and fatal claims) per 100 workers employed all year (per 100 person-years of employment)

\section{Conclusions}

Quantitative risk assessments are becoming common practice for projects with high risks associated with them. A critical step in the risk assessment process is the adoption of risk evaluation criteria. Because of the diverse contexts for which previously defined criteria were proposed, different regions should derive their own criterion or perform an assessment of the applicability of any criteria to be adopted. As such, development of these criteria becomes necessary at a regional, industry, client, and even case specific scales.

The paper proposes a framework for the development of risk-to-life evaluation criteria using landslide hazards as an example, which could be extrapolated to other activities. The framework is developed considering the main aspects involved (system characteristics, the socio-economic, cultural and political context) and the principles for developing the criteria. The framework is linked to the risk management process at its initial steps, ensuring the estimated risks and the defined thresholds are compatible.

The proposed framework basically consists of defining absolute risk thresholds and making a decision on the application of the ALARP principle. This structure was adopted to keep consistency with common practices, and because it has shown its adequacy for risk communication. Methods for the development of risk acceptability and tolerance thresholds are also presented.

A discussion is presented on risk evaluation criteria for residential areas in mountainous terrain. An example of individual risk thresholds for railway employees exposed to landslides is also presented. This is based on accident statistics and comparison to other criteria. These aim to illustrate and discuss some of the issues presented, and highlight that establishing risk evaluation criteria is not an easy task; however, tools are available to propose starting values for stakeholder consultation. The defined criteria, as shown by the examples, are highly dependent on the system being analysed and its context. This implies that the development of the risk evaluation criteria should be an integral part of the risk management framework, where not only the risk analyst takes part, but the regulators, clients and exposed populations participate in establishing the criteria.

\section{Methods}

Given the importance of risk criteria that is adequate for the context of the potential geoenvironmental hazard, this article describes the primary considerations for developing risk evaluation criteria based on an extensive literature review. Based on this review, the authors further propose a framework for defining landslide risk criteria and assess the applicability of previously proposed criteria to a specific context. Two simplified examples discussing some aspects of development of proposed risk evaluation thresholds are discussed for illustration purposes.

\section{Abbreviations}

ACSSL: Adjusted Cost-to-Save-a-Statistical-Life; AGS: Australian Geomechanics Society; ALARP: As Low As Reasonable Practicable; ANCOLD: Australian National Committee on Large Dams; APEGBC: Association of Professional Engineers and Geoscientists of British Columbia; CCPS: Centre for Chemical Process Safety; DNV: District of North Vancouver; ERM: Environmental Resources Management; GCAF: Gross-Cost- of-Averting-a-Fatality; HSE: Health and Safety Executive; IUGS: International Union of Geological Sciences; MOW: Maintenance of Way; NCAF: Net-Cost- of-Averting-a-Fatality;

UCSSL: Unadjusted Cost-to-Save-a-Statistical-Life; UK: United Kingdom

\section{Acknowledgments}

This research was made possible by the (Canadian) Railway Ground Hazard Research Program, which is funded by the Natural Sciences and Engineering Research Council of Canada, Canadian Pacific Railway, Canadian National Railway, and Transport Canada; and the Canadian Rail Research Laboratory (CaRRL) (www.carrl.ca). Special thanks to Dr. Derek Martin, Dr. David Cruden and Dr. Norbert Morgenstern for their valuable insights. None of the authors have any competing interests in the manuscript.

\section{Funding}

This work was made possible through the School of Engineering Safety and Risk Management and the Department of Civil and Environmental Engineering at the University of Alberta.

Availability of data and materials

All information is included in this manuscript. Statistical information used for the examples is publicly available through the references (Statistics Canada, WorkSafeBC). 


\section{Authors' contributions}

Both authors developed the research methodology, wrote the manuscript and approved this submission.

\section{Competing interests}

The authors declare that they have no competing interests.

\section{Publisher's Note}

Springer Nature remains neutral with regard to jurisdictional claims in published maps and institutional affiliations.

\section{Author details}

'David and Joan Lynch School of Engineering Safety and Risk Management, Department of Civil and Environmental Engineering, University of Alberta, 12-324 Donadeo Innovation Centre for Engineering, Edmonton, AB T6G 1H9, Canada. ${ }^{2}$ David and Joan Lynch School of Engineering Safety and Risk Management, 12-287 Donadeo Innovation Centre for Engineering, Edmonton, AB T6G 1H9, Canada.

\section{Received: 4 May 2018 Accepted: 12 July 2018}

\section{Published online: 02 August 2018}

\section{References}

Agrawal, N. 2018. Natural disasters and risk Management in Canada - An introduction. Vol. 366. Netherlands: Springer Nature.

Ale, B.J. 2005. Tolerable or acceptable: A comparison of risk regulation in the United Kingdom and the Netherlands. Risk Analysis 25: 231-241.

Association of Professional Engineers and Geoscientists of British Columbia (APEGBC) (2010) Guidelines for legislated landslide assessments for proposed residential developments in BC. Revised May 2010.

Australian Geomechanics Society (AGS). 2007. Practice note guidelines for landslide risk management 2007. Australian Geomechanics 42 (1): 63-114.

Australian National Committee on Large Dams (ANCOLD). 2003. Guidelines on risk assessment. Melbourne: Australian National Committee on Large Dams Inc.

Aven, T. 2016. Risk assessment and risk management: review of recent advances on their foundation. European Journal of Operational Research 253 (1): 1-13. https://doi.org/10.1016/j.ejor.2015.12.023.

Baecher, G.B., and J.T. Christian. 2003. Reliability and statistics in geotechnical engineering, 605. West Sussex: Wiley,

Bunce, C.M., D.M. Cruden, and N.R. Morgenstern. 1997. Assessment of the hazard from rock fall on a highway. Canadian Geotechnical Journal 34: 344-356.

Cadini, F., G.L. Agliardi, and E. Zio. 2017. Estimation of rare event probabilities in power transmission networks subject to cascading failures. Reliability Engineering and System Safety 158(C: 9-20.

Center for Chemical Process Safety (CCPS). 2009. Guidelines for developing quantitative safety risk criteria. Hoboken: Wiley.

Cha, E.J., and B.R. Ellingwood. 2012. Risk-averse decision-making for civil infrastructure exposed to low-probability, high-consequence events. Reliability Engineering and System Safety 104(C: 27-35.

Clague, J.., and P.T. Bobrowsky. 2010. Natural hazards in Canada. Geoscience Canada 37 (1): 17-37.

Clague JJ, Hungr O, Morgenstern NR, VanDine DF. 2015 Cheekye River (Ch'kay Stakw) and Fan Landslide Risk Tolerance Criteria (pp. 1-77). Squamish: Squamish Nation and its Partnership, and District of Squamish.

Couture, R., A. Blais-Stevens, P. Bobrowsky, B. Wang, and D.F. VanDine. 2013. Canadian technical guidelines and best practices related to landslides. In Landslides: Global Risk Preparedness, ed. K. Sassa, B. Rouhban, S. Briceno, M. McSaveney, and B. He, 317-324. Berlin Heidelberg: Springer-Verlag.

ERM-Hong Kong Ltd. 1998. Landslides and boulder falls from natural terrain: Interim risk guidelines, 183. The Government of Hong Kong Special Administrative Region: ERM-Hong Kong Ltd.

Evans SG (1999) Landslide disasters in Canada, 1840-1998. Geological Survey of Canada, Open File 3712. Available from: https://geoscan.nrcan.gc.ca. Accessed 27 June 2018

Fell, R. 1994. Landslide risk assessment and acceptable risk. Canadian Geotechnical Journal 31: 261-272.

Fell R, Ho KKS, Lacasse S, Leroi E. 2005. A framework for landslide risk assessment and management. Hungr, Fell, Couture and Eberhardt (eds). Landslide risk management, Proceedings of the international conference on landslide risk management, A.A. Balkema, Vancouver, B.C., Canada: 3-25.
Finlay, P.J., and R. Fell. 1997. Landslides: Risk perception and acceptance. Canadian Geotechnical Journal 34: 169-188.

Frank, W., and D. Jones. 2010. Choosing appropriate quantitative safety risk criteria: Applications from the new CCPS guidelines. Process Safety Progress 29 (4): 293-298.

Heitz C, Shimabuku MN. 2017. The role of individuals' risk representations in risk management - case-study on lahars in Arequipa (Peru). Geoenvironmental Disasters 4(28):12

HSE (Health and Safety Executive, UK). 1992. The tolerability of risk from nuclear power stations. London: Her Majesty's Stationery Office.

HSE (Health and Safety Executive, UK). 2001. Reducing risks, protecting people. London: Her Majesty's Stationery Office.

Ho, K.K.S., E. Leroi, and W.J. Roberds. 2000. Quantitative risk assessment application myths and future direction. Proceedings of the international conference on geotechnical and geological engineering (GeoEng2000), 269-312. Australia: Melbourne.

Hungr, O., J.J. Clague, N.R. Morgenstern, D.F. VanDine, and D. Stadel. 2016. A review of landslide risk acceptability practices in various countries. In Presented at the Landslides and Engineered Slopes. Experience, Theory and Practice, Rome, ed. E. A et al., 1121-1128.

IUGS. 1997. Quantitative risk assessment for slopes and landslides - the state of the art. IUGS working group on landslides, committee on risk assessment Cruden and Fell (eds.), Landslide Risk Assessment, Proceedings of the International Workshop on Landslide Risk Assessment, Hawaii. Balkema Rotterdam: 3-12

Khan, F., S. Rathnayaka, and S. Ahmed. 2015. Methods and models in process safety and risk management: Past, present and future. Process Safety and Environmental Protection 98: 116-147.

Leroi E, Bonnard Ch, Fell R, Mclnnes R. 2005. Risk assessment and management. Hungr, Fell, Couture and Eberhardt (eds). Landslide risk management, Proceedings of the international conference on landslide risk management, A.A. Balkema, Vancouver, B.C., Canada: 159-198.

Macciotta, R., C.D. Martin, N.R. Morgenstern, and D.M. Cruden. 2016. Quantitative risk assessment of slope hazards along a section of railway in the Canadian cordillera-A methodology considering the uncertainty in the results. Landslides 13 (1): 115-127. https://doi.org/10.1007/s10346-014-0551-4.

Mignan, A., S. Wiemer, and D. Giardini. 2014. The quantification of lowprobability-high-consequences events: Part I. A generic multi-risk approach. Natural Hazards 73 (3): 1999-2022.

Morgenstern NR (1995) Managing risk in geotechnical engineering. The $3^{\text {rd }}$ Casagrande lecture. Proceedings $10^{\text {th }}$ Pan-American Conference on Soil Mechanics and Foundation Engineering, Guadalajara, Mexico 4: 102-126.

Morgenstern NR. 1997. Toward landslide risk assessment in practice. In Cruden and Fell (eds.) Landslide Risk Assessment, Proceedings of the International Workshop on Landslide Risk Assessment, Hawaii. Balkema, Rotterdam: 15-23.

Morrison J. 2014. The social license. London: Palgrave MacMillan.

Mostyn, G., and T. Sullivan. 2002. Quantitative risk assessment of the Thredbo landslide. Australian Geomechanics 37 (2): 169-181.

Oldenburg, C.M., and R.J. Budnitz. 2016. Low-probability high-consequence (LPHC) failure events in geologic carbon sequestration pipelines and wells: Framework for $L P H C$ risk assessment incorporating spatial variability of risk. Energy geosciences division, Lawrence Berkley National Laboratory, 51. Berkley: University of California.

Pandey, M.D., and J.S. Nathwani. 2004. Life quality index for the estimation of societal willingness-to-pay for safety. Structural Safety 26 (2): 181-199.

Porter, M., M. Jakob, and K. Holm. 2009. Proposed landslide risk tolerance criteria. 62nd Canadian Geotechnical Conference and 10th Joint CGS/IAH-CNC Groundwater Conference, Halifax, Nova Scotia, Canada, 533-541.

Porter, M., and N. Morgenstern. 2013. Landslide Risk Evaluation. In Canadian Technical Guidelines and Best Practices Related to Landslides: a National Initiative For Loss Reduction. Natural Resources Canada, Geological Survey of Canada Open File 7312 Available from: https://geoscan.nrcan.gc.ca. Accessed June 27, 2018.

Porter MJ, Morgenstern NR. 2012. Landslide risk evaluation in Canada. Landslides and Engineered Slopes: Protecting Society Through Improved Understanding, Proceedings of the 11th International and 2nd North American Symposium on Landslides and Engineered Slopes, Banff, AB. Canada 3-8 June 2012. 1:237-243.

Prasad AS, Pandey BW, Leimgruber W, Kunwar RM. 2016. Mountain hazard susceptibility and livelihood security in the upper catchment area of the river Beas, Kullu Valley, Himachal Pradesh, India. Geoenvironmental Disasters 3(3):17. 
Renn, O. 2008. Risk governance: Coping with uncertainty in a complex world. London: Earthscan

Rowe, W.D. 1977. An Anatomy of Risk, 488. NY: Wiley.

Scarlett, L., I. Linkov, and C. Kousky. 2011. Risk Management Practices: Cross-Agency

Comparisons with Minerals Management Service. Resources for the Future, Discussion Paper, 56.

Skjong, R. 2002. Risk acceptance criteria: Current proposals and IMO position. In Surface Transport Technologies for Sustainable Development, Valencia, Spain June 4-6, 2002.

Skjong R, Vanem E, Endresen O. 2005. Risk Evaluation Criteria. Design, Operation and Regulation for Safety - SAFEDOR Project (p. 117). The SAFEDOR Consortium.

Statistics Canada (2010) Mortality, Summary List of Causes 2007, catalogue no. 84F0209X. Electronic file from: www.statcan.gc.ca. Pg. 124. Extracted June 11, 2012.

Statistics Canada (2018) Deaths and age-specific mortality rates by selected group causes, Table 13-10-0392-01. https://www150.statcan.gc.ca. Accessed June 27, 2018.

U.S. Bureau of Reclamation. 2003. Guidelines for achieving public protection in dam safety decisionmaking. Denver: United States Department of the Interior.

Vanem, E. 2012. Principles for setting risk acceptance criteria for safety critical activities. In Advances in Safety, Reliability and Risk Management, ed. Bérenguer Grall and G. Soares, 1741-1751.

Vrijling, J.K., W. van Hengel, and R.J. Houben. 1998. Acceptable risk as a basis for design. Reliability Engineering \& System Safety 59 (1): 141-150.

WorkSafeBC (2009) WorkSafeBC Statistics 2009. Available on line at: http://www. worksafebc.com/publications/reports/statistics_reports Pg. 127. Extracted June 11, 2012.

\section{Submit your manuscript to a SpringerOpen ${ }^{\circ}$ journal and benefit from:}

- Convenient online submission

- Rigorous peer review

- Open access: articles freely available online

- High visibility within the field

- Retaining the copyright to your article

Submit your next manuscript at $\boldsymbol{\nabla}$ springeropen.com 